\title{
Prenatal sonographic evaluation of Arnold Chiari II Malformation
}

\author{
Sadineni Raghu $\mathbf{T}^{1}$, Santh Kumar $\mathbf{B}^{2}$, Praful kumar $\mathbf{K}^{3}$, Chandra Sekhar $\mathbf{K}^{4}$, Chander $\mathbf{B N}^{5}$, Boppana Durga \\ Mahita $^{6}$ \\ ${ }^{1}$ Dr. Sadineni Raghu T, Senior Resident, ${ }^{2}$ Dr. Santh Kumar B, Associate Professor, ${ }^{3}$ Dr. Praful kumar K, Assistant \\ Professor, ${ }^{4}$ Dr. Chandra Sekhar K, Professor, ${ }^{5}$ Dr. Chander BN, Professor \& HOD, above all authors are affiliated with \\ Department of Radiology, Dr. PSIMS \& RF, Chinoutpalli, Gannavaram, Krishna, Vijayawada, Andhra Pradesh 521286, \\ ${ }^{6}$ Dr. Boppana Durga Mahita, Consultant Paediatrician, Rainbow Hospitals, Vijayawada, AP, India.
}

Address for Correspondence: Dr. Sadineni Raghu T, Email: sadineniraghu@ gmail.com

\begin{abstract}
Arnold Chiari malformations are a broad group of malformations with distinctive imaging findings. They are named after an Austrian pathologist Hans Chiari who first identified types I-III in 1891. It is a spectrum of congenital abnormalities of CNS, characterized by downward displacement of the parts of the cerebellum, fourth ventricle, pons and medulla oblongata into the spinal canal. Type II is the most common subtype and is invariably associated with open neural tube defects like myelomeningocele. They constitute an important cause of neonatal morbidity and mortality and hence the need for prenatal evaluation with ultrasound to detect the anomalies. In this article we describe the features of Arnold chiari malformation, illustrate type II cases with sonological parameters for assessment, discuss the findings for diagnosis and conclude with prognosis and management.
\end{abstract}

Key words: Arnold chiari malformation, Meningomyelocele, Lemon sign, Banana sign, Prenatal sonography.

\section{Introduction}

Arnold-Chiari malformation (ACM) is a group of complex brain abnormalities that predominantly affects the region of posterior fossa where the brain and spinal cord meet. It has an incidence of 0.4: 1000 live-births $(0.04 \%)$ and is one of the CNS abnormalities that are responsible for $3 \%$ of all abortions and 1-2\% recurrent risk [1]. It was first described in pediatric autopsy specimens in 1891 by Hans Chiari -Austrian Pathologist (1851-1916) [2]. In legacy with the name of his professor $\mathrm{Dr}$ Arnold, and his name, the hind brain disorder is named as Arnold Chiari malformation [3].

\begin{abstract}
Diagnosis of Arnold chiari malformation is made with prenatal Ultrasound or MRI for evaluation of posterior cranial fossa. Small posterior cranial fossa with descending cerebellar herniation of more than $5 \mathrm{~mm}$ from foramen magnum is considered diagnostic of chiari malformations [4]. There are a variety of sonographic findings, some very specific for Chiari II malformations which include lemon sign, banana sign, hydrocephalus, posterior elements defect in spinal canal and associated myelomeningocele.
\end{abstract}

\section{Materials and Methods}

From a database of obstetric sonograms from radiology department of the institution, we searched for all cases in which a fetal myelomeningocele or features of Arnold chiari malformation were sonographically detected. The search covered three years 2013 to 2016 . We then retrospectively reviewed the fetal intracranial findings in each case. Images included transverse axial planes as well as coronal and sagittal planes when feasible. Features of both normal intracranial anatomy and those associated with the Chiari II malformation were evaluated. A total of 9360 studies and reports were assessed for the presence of Arnold Chiari II malformations. A total of 8 studies with findings consistent with chiari II were obtained and assessed. The incidence rate was calculated as $0.08 \%$.

\footnotetext{
Manuscript received: $5^{\text {th }}$ September 2016

Reviewed: $13^{\text {th }}$ September 2016

Author Corrected: $20^{\text {th }}$ September 2016

Accepted for Publication: $26^{\text {th }}$ September 2016
} 
The studies were performed on Philips HD 15 ultrasound machine with transabdominal probe of 2-6 MHz curved array transducer. Review of the images and reports of respective cases was done.

Findings assessed in particular were for the size of posterior fossa, Lemon sign (loss of normal convex contour of frontal bones giving flattened or inwardly scalloped appearance), Banana sign (anterior curving of cerebellum due to small posterior fossa), Hydrocephalus (width of lateral ventricles $>11 \mathrm{~mm}$ ), spina bifida evidenced by open neural arch, flared laminae, protruding myelomeningocele sac and associations like club foot.

Table-1: Distribution of findings of Arnold chiari II malformation.

\begin{tabular}{|c|c|c|c|c|c|c|}
\hline S No & $\begin{array}{c}\text { Maternal age } \\
(\mathbf{y r s})\end{array}$ & $\begin{array}{c}\text { Gestational } \\
\text { age(weeks) }\end{array}$ & $\begin{array}{c}\text { Posterior } \\
\text { fossa }\end{array}$ & Lemon sign & Banana sign & Hydrocephalus \\
\hline 1. & 25 & 23 & Small & Present & Present & Gross \\
\hline 2. & 30 & 21 & Small & Present & Present & Mild \\
\hline 3. & 20 & 16 & Small & Present & Present & Mild \\
\hline 4. & 26 & 21 & Small & Present & Present & Gross \\
\hline 5. & 28 & 22 & Small & Present & Present & Mild \\
\hline 6. & 26 & 25 & Small & Present & Present & Gross \\
\hline 7. & 25 & 20 & Small & Present & Present & Mild \\
\hline 8. & 21 & 22 & Small & Present & Present & Mild \\
\hline
\end{tabular}

Table-2: Distribution of findings of Arnold chiari II malformation.

\begin{tabular}{|c|c|c|c|c|}
\hline S No & $\begin{array}{c}\text { Spina bifida (Vertebral } \\
\text { arch defect) }\end{array}$ & $\begin{array}{c}\text { Myelomeningo } \\
\text { cele Sac }\end{array}$ & Location & $\begin{array}{c}\text { Club foot } \\
\text { (Rocker-bottom feet type) }\end{array}$ \\
\hline 1. & Present & Present & Dorsolumbar Junction & Absent \\
\hline 2. & Present & Present & Lower lumbar & Absent \\
\hline 3. & Present & Present & Lower lumbar & Bilateral \\
\hline 4. & Present & Present & Dorso lumbar & Absent \\
\hline 5. & Present & Present & Lower lumbar & Bilateral \\
\hline 6. & Present & Present & Lower lumbar & Bilateral \\
\hline 7. & Present & Present & Lower lumbar & Bilateral \\
\hline 8. & Present & Present & Lower lumbar & \\
\hline
\end{tabular}

Prenatal Sonographic Findings: The sonographic findings of Arnold chiari malformation II are as follows:
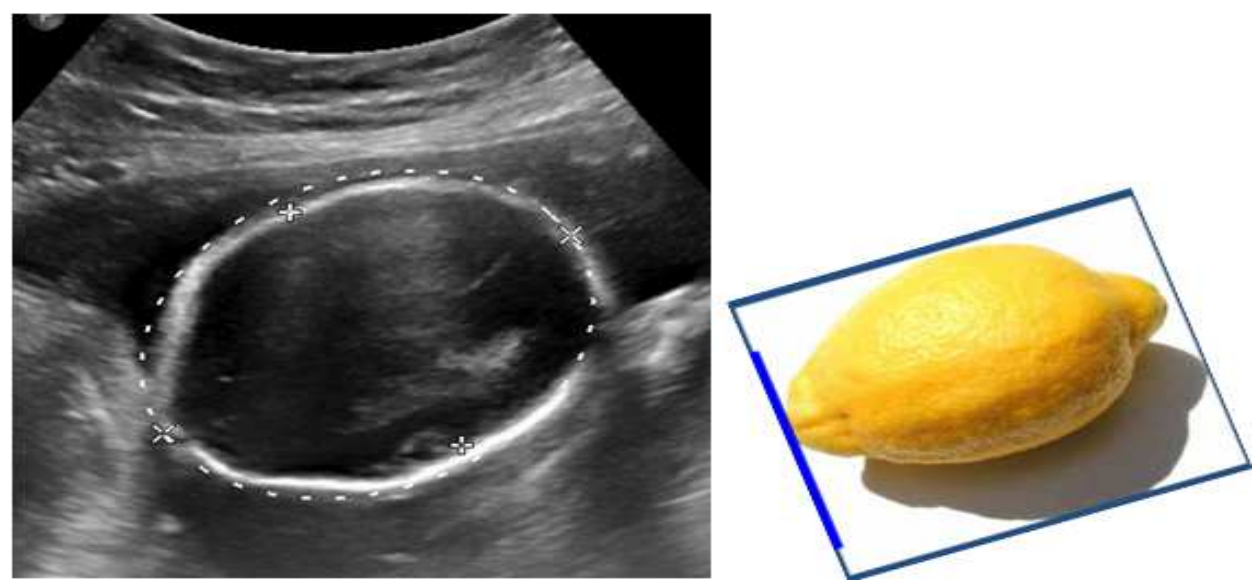

Fig-1.a: Ultrasonographic image of a fetus of 22 weeks gestational age shows classical "lemon sign" with bifrontal inward scalloped appearance. 

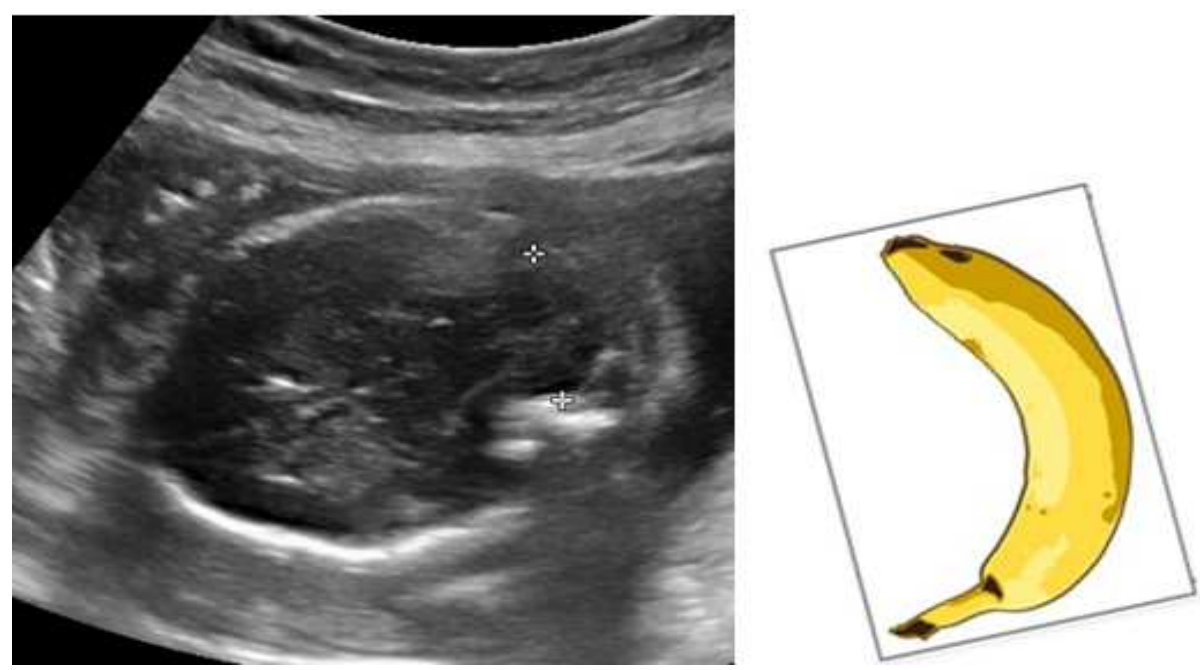

Fig-1.b : Ultrasonographic image demonstrating Banana shaped appearance of elongated cerebellum (marked by cursors) showing small posterior fossa with crowding and effacement of cistern magna.

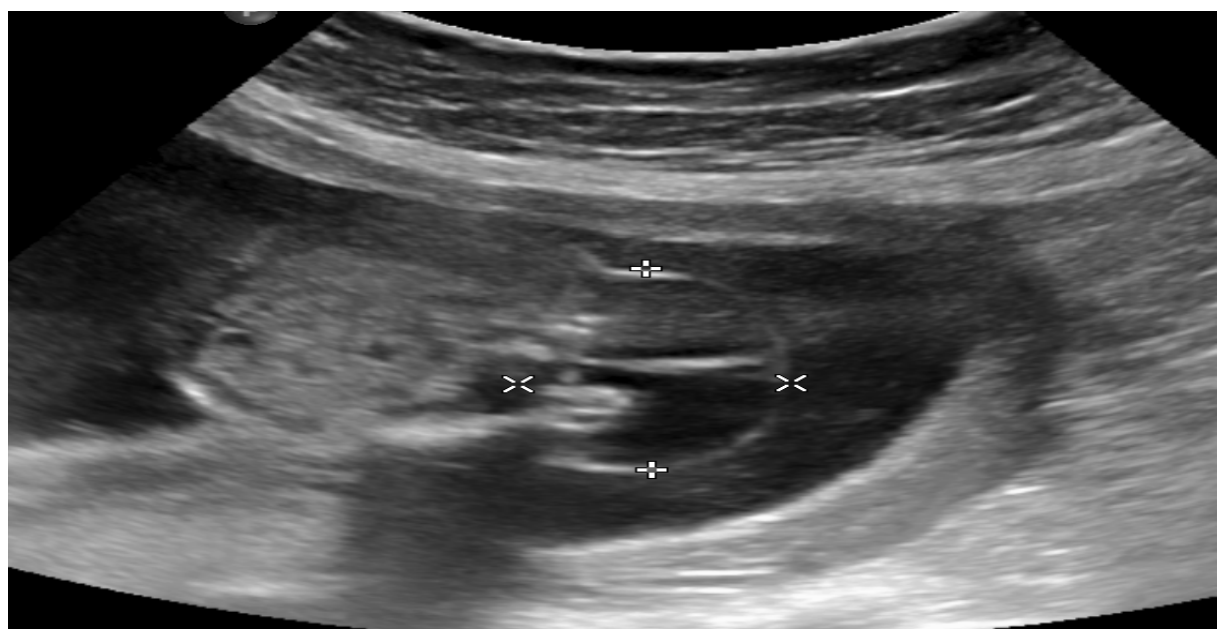

Fig-1.c: Ultrasonographic image demonstrating spina bifida (defect in posterior elements at lumbosacral region) with Myelomeningocele sac.

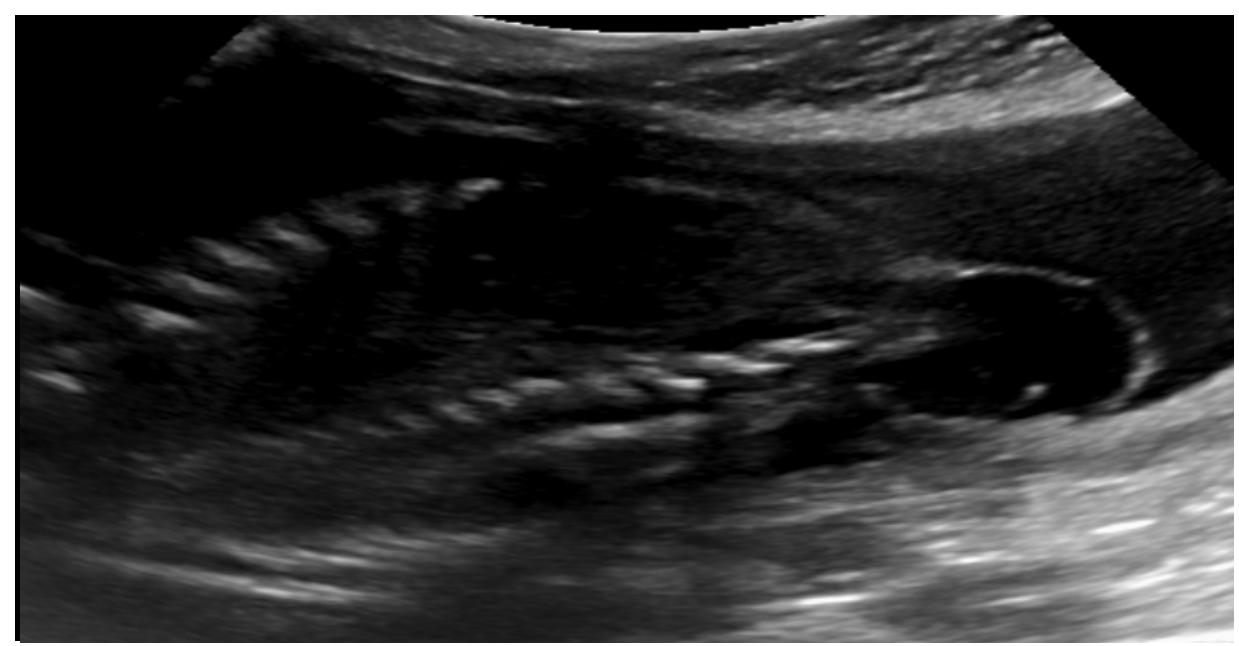

Fig-1.d: Ultrasonographic image demonstrating spina bifida (defect in posterior elements at lumbosacral region) with Myelomeningocele sac. 


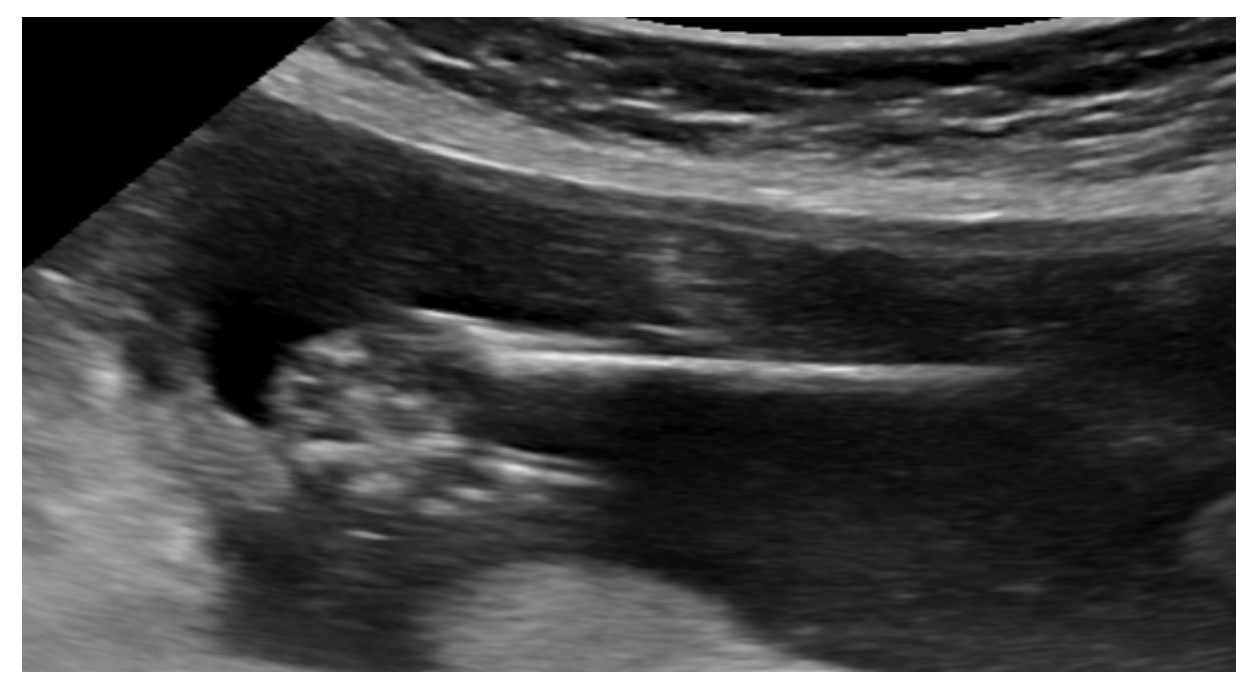

Fig-1.e: Ultrasonographic image demonstrating club foot appearance.

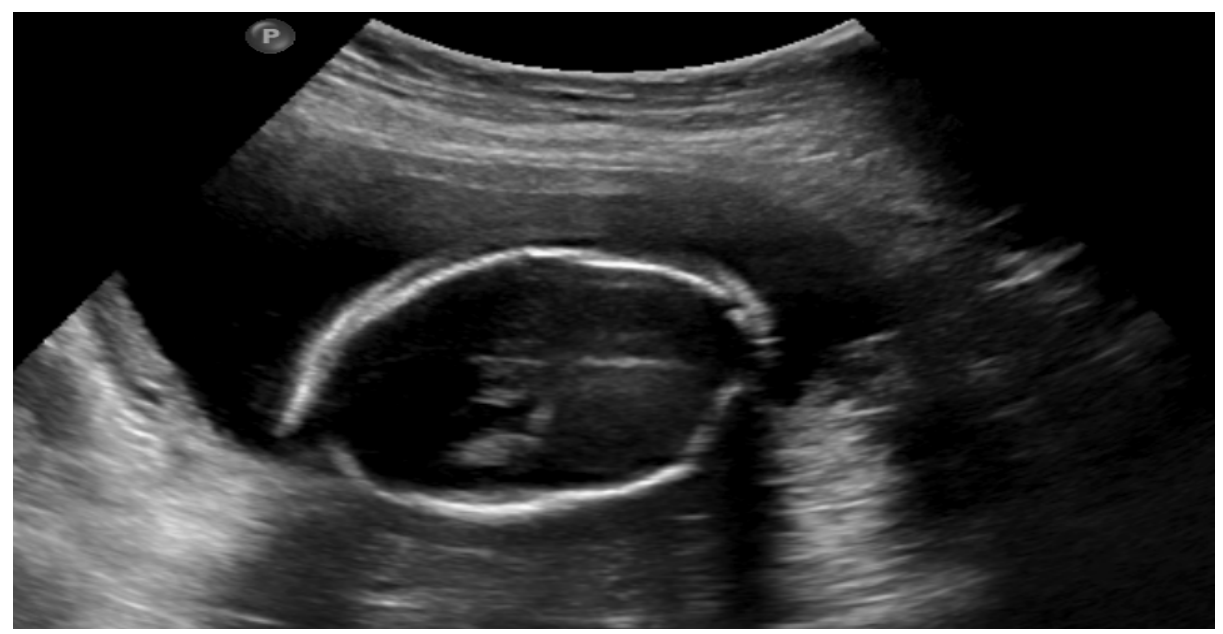

Fig-2 a: Ultrasonographic image of another fetus of 20 weeks gestational age shows classical "lemon sign" with bifrontal inward scalloped appearance.

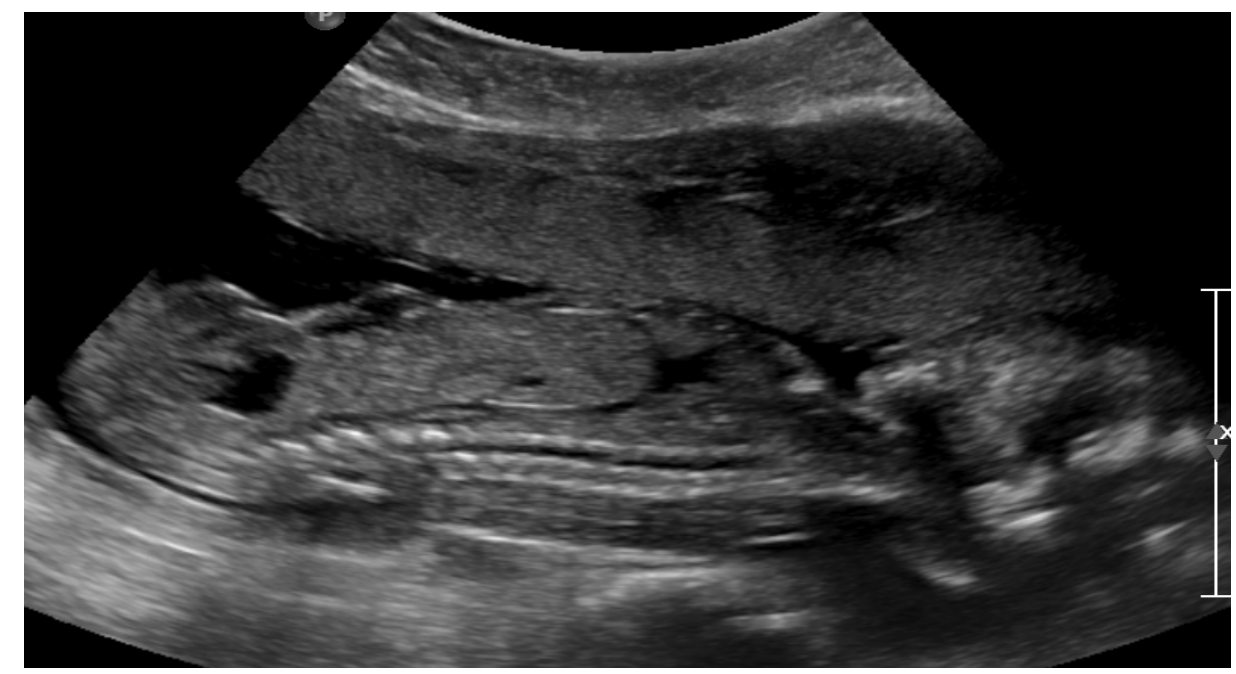

Fig-2 b: Ultrasonographic image demonstrating spina bifida (defect in posterior elements at lumbosacral region). 


\section{Discussion}

Routine anatomic ultrasound performed in the second trimester has a detection rate of approximately $70-90 \%$ for fetal congenital abnormalities [5]. The central nervous system abnormalities are one of the most common ones detected. Chiari malformation is one among the CNS abnormalities diagnosed by prenatal sonography [6]. The obvious sonographic findings are the frontal bone scalloping (lemon sign) and absent cerebellum or abnormal anterior curvature of the cerebellar hemispheres (banana sign) [7]. However, the lemon sign may not be appreciated in later pregnancies and can be seen even in healthy fetuses and in other conditions [8]. On prenatal sonography, characteristic brain findings (lemon sign and banana sign) may be seen as early as 12 weeks and myelomeningocele may be identified as early as 10 weeks. Spina bifida is diagnosed by defect in the posterior elements (open neural arch, flared laminae) and presence of a fluid filled sac like structure corresponding to myelomeningocele with herniation of cerebrospinal fluid and neural elements at the site of defect.

Multiple studies have evaluated the accuracy of sonography for diagnosis of Chiari malformation [9-11]. The feature of the Chiari II malformation that have been most useful are the infratentorial findings, these include effacement of the cisterna magna [9] and deformation of the cerebellum, the so called banana sign, although other infratentorial abnormalities are commonly observed postnatally [10-11]. Few studies have further divided the findings into mild, moderate and severe depending on the severity of narrowing of posterior fossa and alteration in morphology of cerebellum [12]. Descriptors in the literature ranging from" effacement of the fetal cisterna magna" [9] to the bananashaped cerebellum [13] to the absent cerebellum [14] have implied a continuum of severity of PF deformity.

Few supratentorial abnormalities have also been described in literature which include abnormalities in tectal morphologic characteristics (fusion of the colliculi and upward deflection of the tectum result in prominent beaking and elongation of the tectum), altered shape of occipital horn that is pointed rather than rounded [12], corpus callosal dysgenesis, a small third ventricle, enlarged interthalamic adhesions and colpocephaly. These are readily appreciated on post natal imaging by MRI. Rarely, visceral anomalies and other musculoskeletal abnormalities have been described.

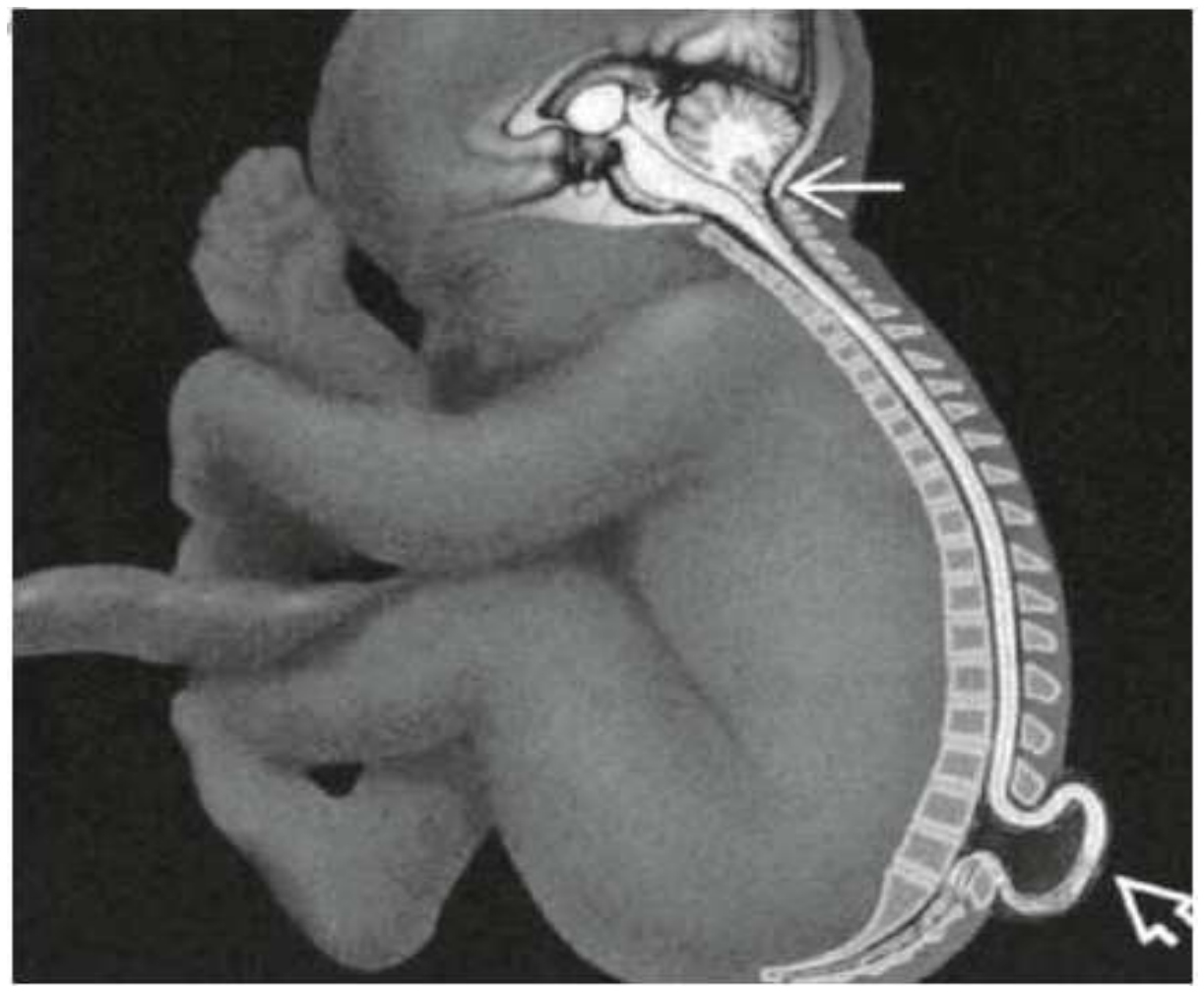

Fig-3: Sagittal diagram of Chiari II malformation with myelomeningocele (open arrow). Hindbrain herniation is the hallmark finding. The cerebellum is herniated (arrow) and the cisterna magna is obliterated [15]. 
There are four types of Arnold chiari malformations described in literature - Types 1 to 4 [16]. These can be confidently diagnosed by post natal MRI evaluation.

Type 1: Herniation of only cerebellar tonsil, not associated with myelomeningocele.

Type 2: Herniation of cerebellar vermis and brain stem into the spinal canal with spina bifida. Features include hydrocephalus, Medullary kink, tentorial dysplasia and is almost always associated with neural tube defects like myelomeningocele.

Type 3: Rare type of brain herniation associated with cephalocele or cranio cervical meningocele in which cerebellum and brain stem may be herniated.

Type 4: Extreme cerebellar hypoplasia and caudal displacement of posterior cranial fossa contents[16].

Tubbs et al described two additional type of chiari malformation [17]

Chiari type 0- Syringohydromyelia with distortion of contents in posterior fossa but without cerebellar tonsillar herniation

Chiari type 1.5- Caudal migration of brainstem and cerebellar tonsils often associated with syringomyelia[18].

In view of the severe morbidity associated with these malformations, a daily intake of $400 \mu \mathrm{gms}$ of folic acid is recommended in the preconception period. A large metanalysis study strongly suggests that gene polymorphism of genes involved in folate metabolite pathway is strongly related to neural tube defects [19]. Many theories have been proposed regarding the exact etiology and causative associations between descending cerebellar herniations and myelomeningocele, however none of them could conclude in detail about the origin and exact mechanism of association [18].

The diagnosis of myelomeningocele in a fetus is important for many reasons. It provides the parents with an opportunity to consider pregnancy termination. Open neural tube defects, can be repaired in utero, as documented recently in the Ochsner experience [20]. The timely closure of spinal defect with seprafilm prevents hind brain herniation. The scar is well healed at birth and the neurological damage is prevented [21]. Among parents electing to continue the pregnancy, adequate counselling and psychological preparation should be provided [22]. Children born with chiari II may present with enlarging head circumference, hydrocephalus, bulbar signs or varying degree of lower extremity paralysis. Hydrocephalus and tethered cord determine prognosis for deterioration.

The main treatment of children born with ACM is to enlarge the foramen magnum and expand the dura by surgical approaches, such as a simple suboccipital craniectomy, craniectomy with C1, C2 laminectomy, duroplasty [23].

\section{Conclusion}

In our study, we have found the features of Chiari II malformation in all the cases consistently and sonography has played the vital role in prenatal diagnosis. The incidence of the malformation is about $0.08 \%$ in our study. At least $50 \%$ of the cases have been associated with club foot. The cranial findings of "lemon" sign and "banana" sign were consistently observed in all cases.

The main prenatal sonographic diagnosis of Arnold chiari II relies on findings such as open neural arch, flared laminae, protruding myelomeningocele sac, and brain findings such as "lemon" sign, "banana" sign and hydrocephalus. There is a declining prevalence of myelomeningocele due to folic acid fortification, prenatal sonographic assessment with termination of affected fetuses and other unknown factors.

The diagnosis of myelomeningocele in a fetus is thus important for many reasons. An option of pregnancy termination can be provided to the parents, or intrauterine interventions may be performed if the parents wish to continue the pregnancy. Adequate counseling regarding the complications and psychological preparation can be provided for such parents. 


\section{Funding: Nil, Conflict of interest: None. Permission of IRB: Yes}

Acknowledgment: Students and staff of Radiology Department, Dr Pinnamaneni Siddhartha Institute of Medical Sciences and Research Foundation, Gannavaram, Vijayawada,AP.

\section{References}

1. Woodward P, Kennedy A, Sohaey R, Byrne JLB, Oh KY, Puchalski MD. Diagnostic imaging. 1sted. Canada, Amirsys Elsevier Saunders. 2005; chapter 2: 21.

2. Tubbs RS, Cohen-Gadol AA. Hans Chiari (18511916). J Neurol. 2010 Jul;257(7):1218-20. doi: 10. 1007/s 00415-010-5529-0. Epub 2010 Mar 26.

3. Sarmah, Prakritish Bora. Arnold Chiarri Malformation Type II. Ped Rad. (serial online)Vol 9, no 10 http://www.kinderradiologie-online.de/radiology/ 20091 018134917. shtml\#.VGWfUzSUcR1.

4. Aboulezz AO, Sartor K, Geyer CA, Gado MH. Position of cerebellar tonsils in the normal population and in patients with Chiari malformation: a quantitative approach with MR imaging. J Comput Assist Tomogr. 1985 Nov-Dec;9(6):1033-6.

5. Nyberg DA, Souter VL. Sonographic markers of fetal trisomies: second trimester. J Ultrasound Med. 2001 Jun; 20(6):655-74.

6. Iruretagoyena JI, Trampe B, Shah D. Prenatal diagnosis of Chiari malformation with syringomyelia in the second trimester. J Matern Fetal Neonatal Med. 2010Feb;23(2):184-6.doi:10.3109/14767050 903061769.

7. Rosenberg HK, Sherman NH, Gubernick JA. Pediatric head, In: McGahan JP, Goldberg BB, ed. Diagnostic ultrasound: A logical approach. 1st ed. Philadelphia, Lippincott-Raven Publishers, 1998; 11351176.

8. Ball RH, Filly RA, Goldstein RB, Callen PW. The lemon sign: not a specific indicator of meningomyelocele. J Ultrasound Med. 1993;12(3):131-134.

9. Goldstein RB, Podrasky AE, Filly RA, Callen PW. Effacement of the fetal cisterna magna in association with myelomeningocele. Radiology. 1989 Aug;172 (2):409-13.

10. McLone DG, Dias MS. The Chiari II malformation: cause and impact. Childs Nerv Syst. 2003 Aug;19 (7-8):540-50. Epub 2003 Aug 12.

11. Barkovich JA. Congenital malformarmation of the brain and skull. In: Barkovich JA(ed). Pediatric Neuroimaging. 4th ed. Philadelphia, PA: Lippincott Williams \& Wilkins; 2005: 378-384.

12. Callen AL, Stengel JW, Filly RA. Supratentorial abnormalities in the Chiari II malformation, II: tectal morphologic changes. J Ultrasound Med. 2009 Jan; 28(1):29-35.

13. Nicolaides KH, Campbell S, Gabbe SG, Guidetti R. Ultrasound screening for spina bifida: cranial and cerebellar signs. Lancet. 1986 Jul 12;2(8498):72-4.

14. Van den Hof MC, Nicolaides KH, Campbell J, Campbell S. Evaluation of the lemon and banana signs in one hundred thirty fetuses with open spina bifida. Am J Obstet Gynecol. 1990 Feb;162(2):322-7.

15. Maryam Nik Nejadi et al, Arnold-Chiari Type II Malformation: A Case Report and Review of Prenatal Sonographic Findings, IJFS, Vol 1, No 4, Feb-Mar 2008.

16. Buoni S, Zannolli R, di Bartolo RM, Donati PA, Mussa F, Giordano F, Genitori L. Surgery removes EEG abnormalities in patients with Chiari type I malformation and poor CSF flow. Clin Neurophysiol. 2006 May;117(5):959-63. Epub 2006 Mar 20.

17. Tubbs RS, Lyerly MJ, Loukas M, Shoja MM, Oakes WJ. The pediatric Chiari I malformation: a review. Childs Nerv Syst. 2007 Nov;23(11):1239-50. Epub 2007 Jul 18.

18. Sharma A, K V Amrutha, Abraham J. Arnold chiari malformation: case series. Int $J$ Anat Res 2016;4(1):2151-2156. DOI: 10.16965/ijar.2016.167

19. Jianxin Jiang, Yanfei Zhang, Liang Wei, Zhiyang Sun, Zhongmin Liu. Association between MTHDI G1958A Polymorphism and neural tube defects susceptibility: A Meta-Analysis. Plos One. 2014;9 (6):e1011169. 
20. Lora Kahn, Nnenna Mbabuika, Edisan P, ValleGiler, Juanita Graces, R. Clifton Moore, et al. Hilaireand Cuong J Bui. Fetal Surgery: The Ochsner experience with in-utero spina bifida repair. The Ochsner Journal. 2014;14(1):112-18.

21. Ganesh D, Sagayaraj BM, Barua RK, Sharma N, Ranga U. Arnold Chiari malformation with spina bifida: a lost opportunity of folic Acid supplementation. J Clin Diagn Res. 2014 Dec;8(12):OD01-3. doi: 10.7860/JCDR/2014/11242.5335. Epub 2014 Dec 5.
22. Callen AL, Filly RA. Supratentorial abnormalities in the Chiari II malformation, I: the ventricular "point". J Ultrasound Med. 2008 Jan;27(1):33-8.

23. Sindou M, Chávez-Machuca J, Hashish H. Craniocervical decompression for Chiari type I-malformation, adding extreme lateral foramen magnum opening and expansile duroplasty with arachnoid preservation. Technique and long-term functional results in 44 consecutive adult cases-comparison with literature data. Acta Neurochir (Wien).2002 Oct;144(10):1005-19.

\section{How to cite this article?}

Sadineni Raghu T, Santh Kumar B, Praful kumar K, Chandra Sekhar K, Chander BN, Boppana Durga Mahita. Prenatal sonographic evaluation of Arnold Chiari II Malformation. Int J Med Res Rev 2017;5(01):88-95. doi:10.17511/ijmrr. 2017.101.13. 